\title{
Radiographic changes in the hands of rock climbers
}

\author{
S. R. Bollen MB FRCS FRCSEd Orth and V. Wright MD FRCP \\ Rheumatism and Rehabilitation Research Unit, University Department of Clinical Medicine, Leeds, UK
}

\begin{abstract}
Radiographs of the hands of 36 rock climbers were compared with radiographs of the hands of controls matched for age and sex. Subchondral cysts were present in the hands of 17 climbers and only two controls. Osteophytes or bony spurs were present in 14 climbers but not in any of the controls, and the only two cases of frank osteoarthrosis were in the hands of climbers. Cortical thickness of the proximal and middle phalanges was significantly greater in the hands of climbers $(P=<0.01)$. Pronounced 'scalloping' of the necks of the proximal phalanges was only seen in climbers, and is due to thickening of the attachment of the distal end of the fibrous A2 pulley of the flexor sheath.
\end{abstract}

Keywords: Rock climbing, arthrosis, fingers

Rock climbing is an increasingly popular sport. The British Mountaineering Council currently has nearly 5000 individual members and 273 affiliated clubs. As equipment and protection techniques have improved in recent years, standards of difficulty in the sport have increased dramatically, with routes becoming steeper and often overhanging, and holds becoming steadily smaller. There is now an international circuit of climbing competitions performed on indoor climbing walls. Regular training is now essential at the top end of the sport, and there are now many purpose built indoor climbing walls on which to practice rock climbing skills throughout the British winter. This puts increasing demands on the upper limbs, particularly the fingers, the joints of which effectively become weight-bearing structures (Figure 1).

Specific injuries of the finger, such as injury to the A2 pulley of the flexor sheath and contractures of the proximal interphalangeal joints, associated with high-standard rock climbing, have already been described $^{1}$. Rock climbers as a group are concerned as to whether their sport is damaging their finger joints, and whether they will develop 'arthritis' in their fingers as they grow older.

A study was set up to investigate whether radiographic changes occurred in the hands of climbers, at an earlier age than in a group of controls.

Address for correspondence: Mr S. R. Bollen MB FRCS FRCSEd

Orth, Consultant Orthopaedic Surgeon, Rheumatism and

Rehabilitation Research Unit, University Department of Clinical Medicine, 36 Clarendon Road, Leeds LS6 9PJ, UK

(C) 1994 Butterworth-Heinemann Ltd

0306-3674/94/030185-02

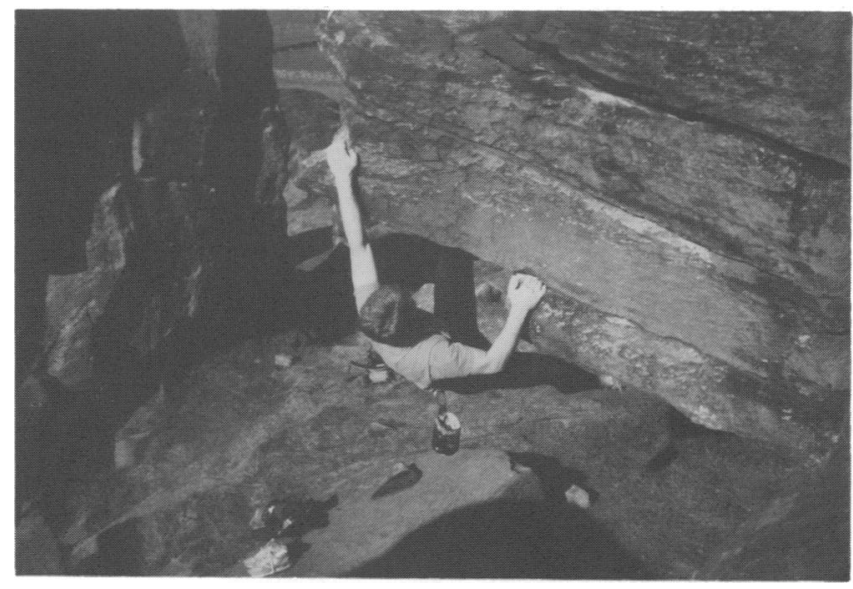

Figure 1. Overhanging climbing makes the fingers weightbearing joints

\section{Materials and methods}

The study included 36 rock climbing men of mean age 31 (range 20-50) years who volunteered to take part in the study. They were either younger 'élite' climbers (including three of four of the British sport climbing team), or had been climbing at a less exacting standard for many years. All subjects were right-hand dominant. A plain anterior-posterior radiograph of both hands on the same plate, of each subject was taken.

As a 'control', each radiograph was compared with a radiograph of the right hand of a subject of the same age and sex, taken in the Accident and Emergency Department for trauma. While this group cannot be an exactly matched set of controls, the majority of young men presenting to casualty for hand trauma either use their hands for making a living or their fists as a method of expression in social interaction.

With a Vernier calliper, using the technique described by Johnston ${ }^{2}$, measurements were made of the cortical thickness at the junction of the distal third and proximal two-thirds of the proximal and middle phalanges of the middle finger of the right hand. This was expressed as a percentage of total width and then compared with the measurement made in the controls.

All right-hand radiographs were then assessed by the two authors for the presence of radiographic abnormalities such as subchondral cysts, osteophytes, joint space narrowing, marginal spur formation and scalloping of the necks of the proximal phalanges. 


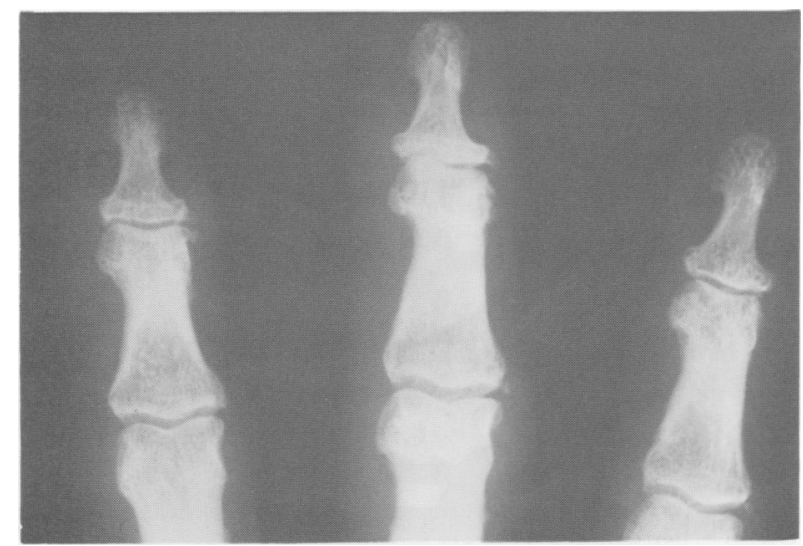

Figure 2. Detached 'spurs' were a common finding as the age of the climber increased

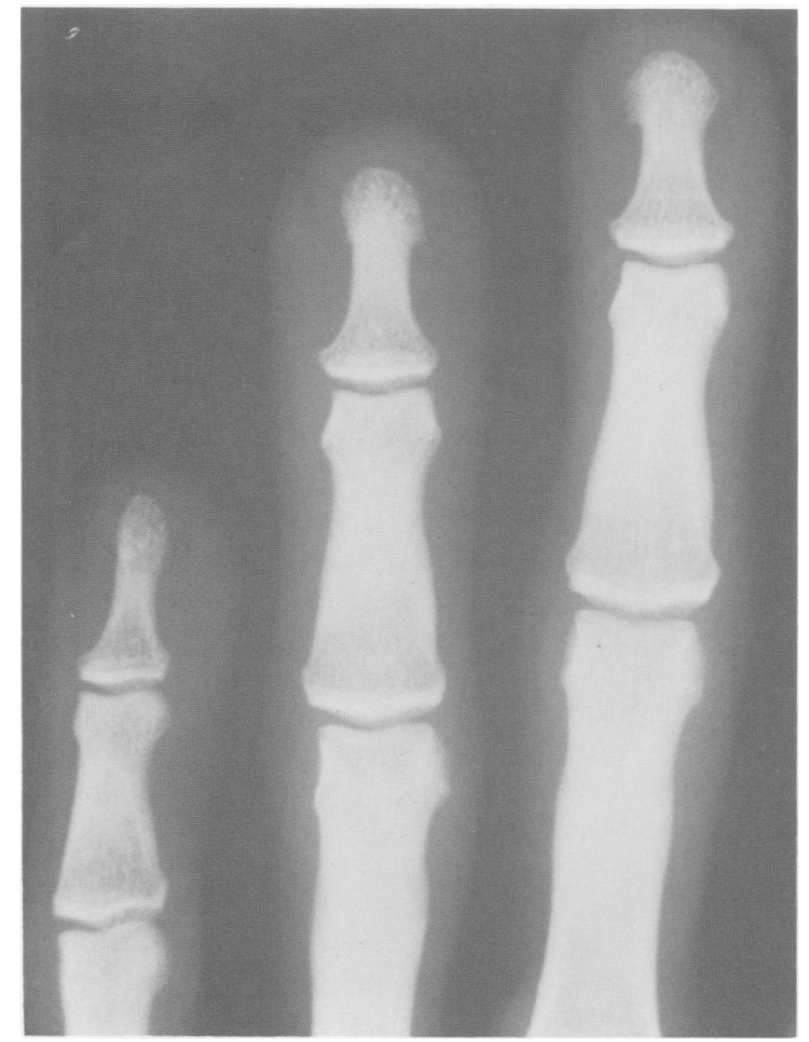

Figure 3. 'Scalloping' of the necks of the proximal phalanges is due to cortical thickening at the attachment of the A2 pulley of the flexor sheath

\section{Results}

Mean cortical thickness as a percentage of total width, of the proximal and middle phalanx in climbers was $70 \%$ and $74 \%$ respectively, compared with $58 \%$ and $52 \%$ in the controls ( $\chi^{2}$ test: $P<0.01$ ). Subchondral cysts were found in the right hands of 17 climbers compared with only two of the controls. Osteophytes (four subjects) and full blown osteoarthrosis (two subjects), only occurred in the hands of climbers over 40 years of age.

An unusual finding in climbers was the appearance of small spurs at the bases of the middle phalanges which became detached as the age of the climber increased (Figure 2). Pronounced scalloping of the necks of the proximal phalanges was also confined to the hands of climbers (12 climbers), and is produced by thickening of the cortices at the attachment of the distal edge of the A2 pulley of the flexor sheath (Figure 3).

\section{Discussion}

While this is not a strictly controlled study, the findings do suggest that climbers develop the radiographic changes of osteoarthrosis, which progress with time. Both of the climbers over 40 years of age complained of some stiffness of the finger joints and aching in cold weather, but all other climbers were asymptomatic.

The worrying aspect of this study is that the older climbers have never climbed at anywhere near the standard that the élite climbers of today can manage. The minute nature of the holds and the increasing steepness of today's hard routes must put a greater strain on the phalanges and interphalangeal joints of the current generation of rock athletes when compared with yesterday's hard men.

It is intended that this study will be used as a baseline and radiographs will be repeated in 5 years to assess whether the radiographic changes have progressed. It will then be seen whether the young stars of the rock climbing world of today, become the gnarly handed, middle-aged adults of tomorrow.

\section{References}

1 Bollen SR, Gunson CK. Hand injuries in competition climbers. Br J Sports Med 1990; 24: 16-19.

2 Conrad C. Non-invasive methods for quantifying appendicular bone mass. In: Avioli LV, ed. The Osteoporotic Syndrome. New York, USA: Grune and Stratton, 1983. 